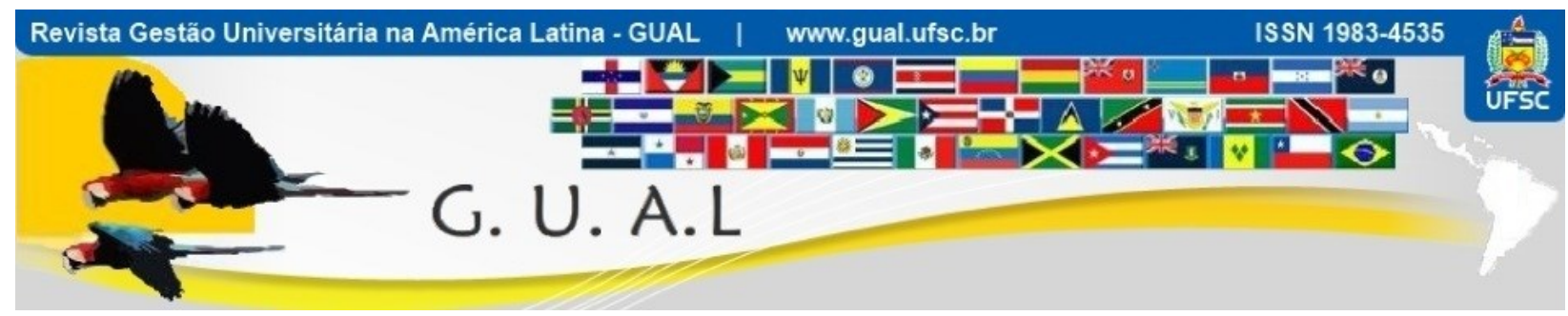

DOI: http://dx.doi.org/10.5007/1983-4535.2016v9n2p154

\title{
EL MÉTODO DE ESTUDIO DE CASO O TÉCNICA CASUÍSTICA: PROPUESTA DE APLICACIÓN EN UNA UNIVERSIDAD DEL VALE DO ITAJAÍ - SC - BRASIL
}

THE CASE STUDY METHOD OR TECHNICAL CASUISTRY: A PROPOSAL IMPLEMENTATION IN A UNIVERSITY OF VALE DO ITAJAÍ - SC - BRAZIL

Raul Otto Laux, Doutor Centro Universitário de Brusque - UNIFEBE raullaux@unifebe.edu.br

Recebido em 04/maio/2014

Aprovado em 17/novembro/2015

Sistema de Avaliação: Double Blind Review

Esta obra está sob uma Licença Creative Commons Atribuição-Uso. 


\title{
EL MÉTODO DE ESTUDIO DE CASO O TÉCNICA CASUÍSTICA: PROPUESTA DE APLICACIÓN EN \\ UNA UNIVERSIDAD DEL VALE DO ITAJAÍ - SC - BRASIL \\ DOI: http://dx.doi.org/10.5007/1983-4535.2016v9n2p154
}

\section{RESUMEN}

Tratase de un artículo científico comparativo entre el método tradicional didácticopedagógico utilizado en las Universidades del Estado de Santa Catarina (Brasil) y la propuesta de una nueva metodología compuesta por las siguientes estrategias innovadoras: (1) método discursivo teórico-práctico, fundamentado en casos ilustrativos reales y actuales; (2) división de las clases en dos o más grupos, cada uno con sus específicas atribuciones en relación a la temática en foco (defensa - contestación), como motivador de debates prácticos; (3) interacción entre clases distintas, a modo de enriquecimiento del debate temático; (4) consenso de las soluciones presentadas por los distintos grupos mediante el debate final. La propuesta que defiende esta dinámica se basa en la desconstrucción de los métodos tradicionales, reconstruyéndolos al mismo nivel de la realidad fáctica social (método de casos), de manera que lo que se privilegie sea la práctica, aunque sin olvidarse la teoría. Por la superposición continuada del aspecto práctico sobre el fundamento teorético, la asimilación de nuevos conocimientos adquiere contornos concretos de inmediata comprensión, adherencia y aplicabilidad, facilitando el aprendizaje del alumno. Aunque este método venga siendo aplicado desde antaño (la Universidad de Harvard ya lo aplicaba en su Facultad de Derecho, a partir de 1870), parece haber cierta contrariedad con su función práctica en otras ramas científicas, a ejemplo de la Administración, Pedagogía, Economía, etc. Con todo, no nos parece que sea inadecuado aplicárselo a distintas áreas - como la de Pedagogía -, pues la práctica facilita la comprensión y la asimilación más rápidamente que la discusión simplemente teórica. La defensa de este presupuesto es nuestro objetivo central de esta propuesta.

Palabras-Clave: Didáctica. Pedagogía. Método. Empirismo. Casos.

\begin{abstract}
This comparative scientific paper deals with the relationship between traditional didactic teaching method used in Universities of the State of Santa Catarina (Brazil) and the proposal of a new methodology consisting of the following innovative strategies: (1) theoretical practical discursive method based on real and current illustrative cases; (2) division of the class-room groups in two or more of them, each one with its specific attributions as regards the subject-matter in focus (defense - answer), as a motivation of practical debates; (3) interaction between different classroom, as enrichment of the thematic debate; (4) consensus of the solutions presented by different groups through the final debate. The proposal that defends this dynamic is based on the deconstruction of the traditional methods, rebuilding at the same level of social reality factual (case method), so that what would privilege is the practice, although without forgetting the theory. By the overlap of continued practical aspect on the basis theoretical, the assimilation of new knowledge acquired contours of concrete immediate understanding, adhesion and applicability, facilitating student learning. Although this method has being applied from formerly (the University of Harvard was already applying it in its High School of Law, from 1870), there seems to be certain contrariety with its practical function in other scientific branches, as the examples of Administration, Pedagogics, Economy, etc. However, it does not seem to us that it is inadequate to apply it to him at different areas - such us Pedagogy - since the practice facilitates the comprehension and the assimilation more quickly than the simply theoretical discussion. The defense of this assumption is our central target of this proposal.
\end{abstract}

Keywords: Teaching. Education. Method. Empiricism. Cases. 


\section{EL MÉTODO DE ESTUDIO DE CASO O TÉCNICA CASUÍSTICA: PROPUESTA DE APLICACIÓN EN \\ UNA UNIVERSIDAD DEL VALE DO ITAJAÍ - SC - BRASIL \\ DOI: http://dx.doi.org/10.5007/1983-4535.2016v9n2p154}

\section{INTRODUCCIÓN}

La enseñanza superior mundial, a partir de la década del 60 (siglo XX), ha venido alterando sus indicadores numéricos en varios aspectos, entre los cuales se destacan dos: el creciente aumento de la matrícula y una diversificación en sus opciones educativas. En relación al primer factor, la década del 60 cuantificaba trece millones de estudiantes en el tercer grado (números mundiales), número que, en 1995, ya alcanzaba los ochenta y dos millones de alumnos universitarios, con una previsión de llegar a los noventa millones en el $2000^{1 / 2}$. Este último número acabó siendo superado en nada menos que un $10 \%$, llegando a los 99,5 millones en el final del siglo pasado, con una estimación de alcanzar en 2035 algo en torno de los 520 millones (un aumento de más de $500 \%$ en apenas treinta y cinco años) ${ }^{3}$. Una de las causas de mayor peso para dicho crecimiento, según el estudio de la UNESCO, sería la expansión de la enseñanza secundaria, cuyos números ascendentes acompañan de cerca los del crecimiento del nivel universitario: “el número de alumnos de esta enseñanza en el mundo pasó de 91 millones a 372 y los índices brutos de matriculación se duplicaron pasando de 29\% a 58\%"4. Estos índices, cuando buscados en el universo de los países desarrollados, llegan a alcanzar el 99\% en la enseñanza secundaria, tornándola muy próximo de lo universal.

Sin embargo, existen otros indicadores que no parecen ser tan auspiciosos cuanto los recién expuestos, cuando se trata de evaluar el desempeño del Brasil educacional en relación al bloque de la OCDE (Organización para la Cooperación y el Desarrollo Económico). Un estudio de Nelson Cardoso Amaral (Universidade Federal de Goiás), Doctor en Educación, expone números actualizados, presentados durante la $36^{\mathrm{a}}$ Reunião Nacional da ANPEd (Associação Nacional de Pós-Graduação e Pesquisa em Educação - Brasília - DF). Manteniendo como marco referencial la década de 1960, tendríamos que los jóvenes de esa época con edad entre 18 y 24 años (faja etaria adecuada para el ingreso a la universidad) representaban una tasa bruta de participación en la educación superior en torno del 1,5\% correspondiente a apenas 142.386 estudiantes matriculados de un contingente de casi diez

\footnotetext{
1 Asociación Nacional de Universidades e Instituciones de Educación Superior - ANUIES. La educación superior en el siglo XXI. Líneas estratégicas de desarrollo. México, DF: ANUIES, 2000.

${ }^{2}$ UNESCO-PARIS. La educación superior en el siglo XXI. Visión y acción. Paris: UNESCO, 1998. Disponible en: < http://unesdoc.unesco.org/images/0011/001163/116345s.pdf>. Acceso en: Abril.2015.

${ }^{3}$ GANDINI, Verónica. Una mirada a la situación actual de la Educación Superior Mundial y su tendencia. In: Academia.edu. 2013.

Disponible en: http://www.academia.edu/5147698/Una_mirada_a_la_situaci\%C3\%B3n_actual_de_la_Educaci\%C3\%B3n_Supe rior_Mundial_y_su_tendencia>. Acceso en: Abril. $\overline{2015}$.

${ }^{4}$ UNESCO-PARIS, op.cit., p. 3.
} 


\section{EL MÉTODO DE ESTUDIO DE CASO O TÉCNICA CASUÍSTICA: PROPUESTA DE APLICACIÓN EN \\ UNA UNIVERSIDAD DEL VALE DO ITAJAÍ - SC - BRASIL \\ DOI: http://dx.doi.org/10.5007/1983-4535.2016v9n2p154}

millones de jóvenes -. Esa tasa bruta participativa, en 2011, alcanzaba apenas el 14,3\% (Censo da Educação Superior de 2011), no obstante todos los estados de la Federación ya contasen con IES instaladas ${ }^{5}$ - ante el objetivo pretendido por el Gobierno de alcanzar la tasa bruta del 50\%, un desafío aparentemente difícil y distante.

Un estudio comparativo realizado por el Plano Nacional de Educação (PNE), gubernamental, mensuró los años 2001 y 2013 - vea Ilustración 1 - exponiendo un salto substancial de la tasa bruta participativa en ese periodo, a par en que contestaba los indicadores del Censo da Educação Superior (de 2011), como visto en acápite anterior: de $16,5 \%$ (en 2001), la tasa bruta saltó para el 32,3\% (en 2013), un dato curioso que expone las divergencias entre órganos estatales que evalúan los índices de la educación superior.

El Plano Nacional de Educação (PNE) ${ }^{6}$, subráyese, es un programa reciente de gobierno del Ministério da Educação brasileño, aprobado por la Ley $\mathrm{N}^{\mathrm{o}} 13.005$, del 25 de junio de 2014, cuya vigencia está prevista para diez años durante los cuales son definidos diversos programas en estrecha coparticipación con los organismos gestores de la educación en los estados y municipios de la Federación. Define las políticas educacionales en amplio sentido y determina las directrices de base para el periodo previsto. Ahora bien, en este Plano de alcance decenal no existe ningún determinante programático que verse sobre cualquier alteración y perfeccionamiento substancial en las metodologías didáctico-pedagógicas tradicionales. ¿Por qué?

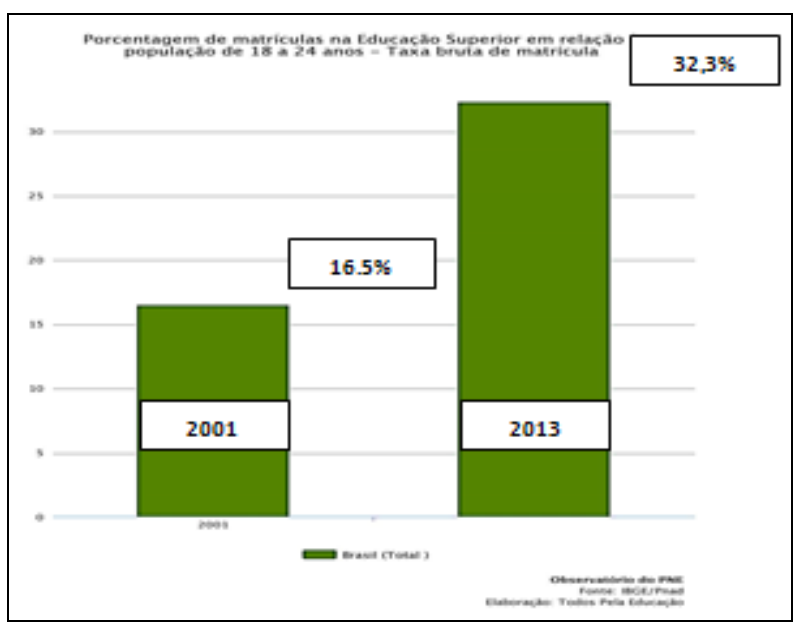

Ilustración 1 Comparación Tasa Bruta 2001 - 2013 - Brasil. Fuente: Observatório do PNE (2013).

\footnotetext{
${ }^{5}$ AMARAL, Nelson Cardoso. A educação superior brasileira: dilemas, desafios e comparações com os países da OCDE e do BRICS. In: $36^{\text {a }}$ Reunião Nacional da ANPEd - 29 de setembro a 2 de outubro. Goiânia: ANPEd, 2013, p. 2.

${ }^{6}$ BRASIL - MINISTÉRIO DA EDUCAÇÃO. Plano Nacional de Educação - PNE. Disponível em: $<$ http://portal.mec.gov.br/index.php?option=com_content\&id=16478\&Itemid=1107>. Acesso em: Abril.2015.
} 


\section{EL MÉTODO DE ESTUDIO DE CASO O TÉCNICA CASUÍSTICA: PROPUESTA DE APLICACIÓN EN \\ UNA UNIVERSIDAD DEL VALE DO ITAJAÍ - SC - BRASIL \\ DOI: http://dx.doi.org/10.5007/1983-4535.2016v9n2p154}

Sería comprensible esa ausencia de novedades si efectivamente los niveles de asimilación y de comprometimiento del alumnado estuvieran creciendo; sin embargo, esto no se constata en la práctica generalizada. Y no apenas en los cursos universitarios, sino que también en los grados inferiores - primario y secundario. Las prácticas pedagógicas siguen siendo aquellas utilizadas en la década de 1960, a excepción de la utilización (en ciertos casos específicos) de las tecnologías microinformáticas.

\subsection{DIDÁCTICA Y PEDAGOGÍA: DESAFÍOS PERMANENTES EN LA EDUCACIÓN SUPERIOR}

Aclaremos algunos conceptos pertinentes al tema. La didáctica (del griego didaskein $=$ proceso de instrucción) fue sistematizada en 1638 por Jan Amós Comenius ("Didactica Magna”), considerado actualmente el padre de la Pedagogía Moderna. Por sus lecciones se infiere que la didáctica nada más es sino el arte de enseñar, rompiendo el eslabón con las ideas entonces vigentes, de perfil conservador, impuestas por el clero y la nobleza. A este estudioso se atribuye el avance revolucionario de enfatizar los medios y los procesos, en detrimento de la formación de un hombre ideal (objetivo prioritario hasta entonces). Amerita aclararse que la sociedad de la época se enfrontaba con el creciente fortalecimiento del sistema de producción capitalista. "Este sistema exigía que la enseñanza se volviera para el mundo de la producción y de los negocios, contemplando el desarrollo de las capacidades y los intereses individuales"

La didáctica no debe ser su-considerada, restringiéndola a una simple renovación en las formas de enseñar y aprender. "[...] la didáctica - asevera y refuerza Scheibel - tiene como compromiso buscar prácticas pedagógicas que promuevan una enseñanza realmente eficiente, con significado y sentido para los educandos [destacamos], y que contribuyan para la transformación social"8. Es en este especial sentido que se debe subrayar su núcleo propio de estudios (relación enseñanza-aprendizaje) en el cual se insertan sus objetivos, contenidos, métodos y configuración organizativa del proceso de enseñanza. Por otro ángulo, no se debe olvidar que el proceso relacional enseñanza-aprendizaje impone un cierto estándar de calidad durante todos los niveles escolares. En este sentido, uno de los problemas más graves que existen en Brasil - a pesar de esfuerzos inestimables en el sentido de minorarlos -

\footnotetext{
7 SCHEIBEL, Maria Fani. Didática, identidade profissional e contextualização da prática docente. In: "Didática: Organização do trabalho pedagógico", Ana Claudia Urban, Christiane M. Maia, Maria Fami Scheibel. Curitiba: IESDE Brasil, 2009, p. 14.

${ }^{8}$ SCHEIBEL (op.cit.), p. 14.
} 


\section{EL MÉTODO DE ESTUDIO DE CASO O TÉCNICA CASUÍSTICA: PROPUESTA DE APLICACIÓN EN \\ UNA UNIVERSIDAD DEL VALE DO ITAJAÍ - SC - BRASIL \\ DOI: http://dx.doi.org/10.5007/1983-4535.2016v9n2p154}

es el conjunto significante de problemas ya en la enseñanza fundamental ${ }^{9}$, tornando frágil la base de sustentación de toda la estructura educacional posterior.

Si la formación académica del profesor es frágil, su desempeño en el quehacer educativo podrá, muy probablemente, también serlo. Un ejemplo de lo afirmado es el aspecto de que, cuando se aborda el tema de "formación de profesores", lo primero que surge en la mente es la asociación con el proceso de formación para la docencia en la educación básica (enseñanza fundamental) y máxime media (Liceo o Segundo Grado). "Difícilmente el abordaje de formación de profesores se extiende a la formación de profesores universitarios, como si la formación específica para el magisterio en ese nivel fuera algo superfluo, o mismo, desnecesario" $"$.

Un estudio profundo sobre "las repercusiones del conocimiento didáctico en la formación del profesor universitario, aprehendidas por medio de su discurso pedagógico sobre su propia práctica, y sobre la comprensión de la docencia realizada en cursos de actualización didáctico-pedagógicos para profesores universitarios"11, parte del siguiente postulado: la imposición de comprenderse las demandas internas de la universidad atiende a la exigencia de perfeccionamiento del magisterio público superior (acreceríamos también el privado), además de también atender a las exigencias sociales externas,

[...] en fase de las rápidas y complejas mudanzas de la sociedad capitalista globalizada, que exigen, en una tendencia crítica, un nuevo perfil del profesional docente, con una visión integrada de mundo, con actuación competente, comprometida con las problemáticas políticas, socioculturales, técnico-científicas, ecológicas, estéticas, de orden moral y ética, etc. ${ }^{12}$

Por otros términos, la Academia, hoy, es experimental-objetiva, utilitaria en su génesis, proactiva, constructora de un nuevo conocimiento calcado en su validación práctica, matemática, eficaz, ejecutable en amplio sentido. No sobra espacio para elucubraciones, desgastantes y soporíferos discursos teoréticos, cuando disociados de la comprobación práctica y útil del conocimiento. Es, en suma, la pedagogía posmoderna, participativa,

\footnotetext{
${ }^{9}$ En Brasil, la enseñanza fundamental comprende nueve años $\left(1^{\circ}\right.$ al $\left.9^{\circ}\right)$ y se aplica a niños/niñas de la faja etaria entre los seis y catorce años. Esos problemas son de mayor significancia en toda la red pública educativa, de sufrible calidad, y se extienden a la enseñanza media pública (Liceo), en que tales problemas se multiplican, dificultando la preparación básica y media el alumno que pretende ingresar a una universidad (N.A.).

${ }^{10}$ SILVA, Vanius Paiva Zaiden. Formação didático-pedagógica do professor universitário: uma necessidade? Consuelo Campos Monteiro (Orientadora). In: Fundação Aprender. Varginha: APRENDER, 2006 [documento eletrônico].

${ }^{11}$ MELO, Márcia Maria de Oliveira. Repercussões do conhecimento didático sobre a formação de professores universitários em curso de atualização docente. In: "Reflexões e práticas em pedagogia universitária", Maria Isabel da Cunha (Org.). Campinas, SP: Papirus, 2007, p. 93.

${ }^{12}$ Ibidem, p. 94.
} 


\section{EL MÉTODO DE ESTUDIO DE CASO O TÉCNICA CASUÍSTICA: PROPUESTA DE APLICACIÓN EN \\ UNA UNIVERSIDAD DEL VALE DO ITAJAÍ - SC - BRASIL \\ DOI: http://dx.doi.org/10.5007/1983-4535.2016v9n2p154}

interactuante, inclusiva, por la cual la praxis asume singular relevancia, al paso que también pulveriza la sólida y perenne barrera entre docente y discentes, congregándolos hacia un mismo objetivo: el enseñar/aprehender participativo.

Cabe aquí una cuestión pertinente: ¿Por qué toda esa preocupación generadora de amplios y exacerbados debates sobre metodología didáctico-pedagógica, fundamentando la publicación de incontables obras literarias al respecto? La respuesta parece residir en la necesidad apremiante de renovación de los abordajes metodológicos en validad, ante el contingente creciente de alumnos que ingresan a la universidad, aunque no apenas en este indicador. Otras variables interfieren en este fenómeno, como bien lo exprimen Engers \& Morosini, dos destacados estudiosos del tema. Para estos investigadores, "el momento actual exige mudanza de foco, tanto del profesor como del alumno, y consecuentemente de la Enseñanza Superior"13. La realidad social del nuevo milenio y sus programas sociales inclusivos alteraron substancialmente el perfil del alumno universitario, tornándolo una variable heterogénea. Las avanzadas y masificadas Tecnologías de la Información y de la Comunicación (TICs) abrieron de par en par las puertas de la información y de la interrelación individual y colectiva, a través de innúmeros recursos que popularizaron el acceso a ellas. Sin embargo, las clases presenciales aún continúan siendo mayoritarias - a ejemplo de los EUA, que las mantienen en un 75\%, o del Brasil, que ronda los 98\%. El censo Inep/MEC 2012 cuantificó poco más de siete millones de alumnos estudiando en universidades. De este contingente, casi seis millones son en cursos presenciales y apenas un millón y cien mil alumnos cursan la enseñanza universitaria a distancia ${ }^{14}$.

Las TICs, no se dude, han contribuido con beneficios a la enseñanza universitaria, como la comunicación, colaboración y distribución de los conocimientos; la atención personalizada y el seguimiento del alumno; la posibilidad de autoevaluaciones e coevaluaciones del aprendizaje; la iniciativa, originalidad y creatividad; la investigación, selección, valoración y organización de la información; entre otras ventajas ${ }^{15}$. Sin embargo, los métodos del binomio enseñanza x aprendizaje persisten en una didáctica "enyesada", casi estática, que parece insistir en la dinámica teorética, cuando lo que hoy el mercado demanda

\footnotetext{
${ }^{13}$ ENGELS \& MOROSINI (2007) Apud VITÓRIA, M. I. C.; CHRISTOFOLI, M. C. P. Estratégias didáticas com grandes grupos. In: "Capacitação docente: um movimento que se faz compromisso", Ana Lúcia Souza de Freitas [et al] (Orgs.). Porto Alegre: EDIPUCRS, 2010, p. 114.

14 ABRES - Associação Brasileira de Estágios. Matrículas na Educação. Disponível em: $<$ http://www.abres.org.br/v01/stats/>. Acesso em: Maio.2015.

15 BENITO, Agueda; CRUZ, Ana. Nuevas claves para la Docencia Universitaria en el espacio europeo de Educación Superior. Madrid: NARCEA Ediciones; Universidad Europea de Madrid, 2005.
} 


\section{EL MÉTODO DE ESTUDIO DE CASO O TÉCNICA CASUÍSTICA: PROPUESTA DE APLICACIÓN EN \\ UNA UNIVERSIDAD DEL VALE DO ITAJAÍ - SC - BRASIL \\ DOI: http://dx.doi.org/10.5007/1983-4535.2016v9n2p154}

es la experimentación, la utilidad práctica del conocimiento que, por su vez, realimente el proceso creativo del alumno. Recordemos que las TICs facilitan la aprehensión de la información, que exige una crítica y responsable selección, reteniendo lo servible y desechando lo inservible o redundante. En otras palabras, la sistemática del estudio se complicó al elevar a la enésima potencia las fuentes a disposición del académico, tornando más compleja su elección. ¿Sería, entonces, una ventaja o una barrera impeditiva a más para el estudiante?

Una ponencia de Elisa Lucarelli permite que aclaremos un poco más ese escenario de expresivas mudanzas por las cuales pasa nuestra formación intelectual en las instituciones educativas latinoamericanas en general, con diferenciado énfasis para las universidades. Iniciemos reproduciendo una premisa acuñada por dicha estudiosa, cuando apunta hacia cierta disonancia entre la teoría y la praxis didáctico-pedagógica por cuenta de "una penosa historia de innovaciones ajenas a su idiosincrasia e impuestas a sus actores con la engañosa ilusión de transformar sus realidades cotidianas en pos de un mejoramiento de la calidad de los servicios educativos" $" 16$. Exigir innovación en la práctica docente conlleva a diferenciar entre un modelo innovador con foco en los protagonistas y la innovación puramente tecnicista sin descuidar de la relación teoría - praxis, bien como "aportar información acerca de los niveles en que esa articulación se expresa en las prácticas en el aula universitaria" ${ }^{17}$, completa Lucarelli.

Sintetizando por otro camino explicativo, todo el proceso de innovación de la práctica docente, a fin de tornarla más eficaz, efectiva y de acuerdo a la realidad, es construir "una malla curricular por competencias, créditos y el enfoque de problemas"18, lo que podemos entender como siendo un módulo formativo o diseño curricular por competencias ${ }^{19}$. Asimismo, a través de una hipotética lente analítica ampliada, sería razonable afirmar que el diseño curricular por competencias comparte varios aspectos en común con el método de estudio de caso. Ilustrando lo afirmado, examinamos algunos estudios sobre aprendizaje organizacional elaborados por autores bien cotizados en esta área, que nos permiten ratificar

\footnotetext{
${ }^{16}$ LUCARELLI, Elisa. Las prácticas innovadoras en el aula universitaria: Una mirada desde la investigación. In: "Práticas inovadores na aula universitária. Possibilidades, desafíos e perspectivas". Beatriz Maria Boéssio Atrib Sanchet; Gomercindo Ghiggi (Orgs.). São Luis, MA: EDUFMA, 2009, p. 18.

${ }^{17}$ Ibidem.

18 TOBÓN, S.; RIAL, A.; CARRETERO, M. A..; GARCÍA, J. A. Diseño y gestión de módulos por competencias en educación superior. In: "Competencias, calidad y educación superior", José Vicente Joven Núñez (Dir.Ed.). Bogotá: Cooperativa Editorial Magisterio, 2006, p. 168.

${ }^{19}$ La obra de Tobón, Rial, Carretero y García, referenciada en la Nota 18 (supra), se muestra adecuada a la profundización de este tema y a la adecuación de su contenido dentro de los contornos de Estudios de Caso, objeto de esta ponencia (N.A.).
} 


\section{EL MÉTODO DE ESTUDIO DE CASO O TÉCNICA CASUÍSTICA: PROPUESTA DE APLICACIÓN EN \\ UNA UNIVERSIDAD DEL VALE DO ITAJAÍ - SC - BRASIL \\ DOI: http://dx.doi.org/10.5007/1983-4535.2016v9n2p154}

esa aproximación entre el diseño curricular por competencias y el método de estudio de caso, como lo exponemos a continuación.

\subsection{NUEVA ORDEN ECONÓMICA MUNDIAL Y LA DIDÁCTICA EXPERIMENTAL}

Manuel Castells, sociólogo español contemporáneo de larga visión de mundo, ha subrayado en sus escritos que las últimas dos décadas testifican la importancia y el interés creciente en el conocimiento y en el aprendizaje como impulsores del desarrollo socioeconómico, apodándolas como la nueva orden económica informacional y global, "dado que la productividad y la competitividad de las unidades económicas, sean ellas empresas, regiones o naciones, dependen de la capacidad de generar, procesar y aplicar eficazmente la información basada en el conocimiento" 20 . No obstante información y conocimiento hayan sido desde siempre variables determinantes del desarrollo económico, el énfasis que Castells les atribuye no es despropositada ni tampoco infundada; tiene su razón de ser fundamentada en el expresivo desenvolvimiento de las TICs (como ya lo citáramos más arriba), al aproximar los polos más distantes del planeta en fracciones de segundos y al toque de una tecla, imprimiendo una dinámica comunicacional jamás experimentada por el hombre. El planeta se tornó pequeño ante eses avances tecnológicos.

En las propias palabras de Castells:

Un nuevo mundo está tomando forma en este fin de milenio. Se originó en la coincidencia histórica, hacia finales de los años sesenta y mediados de los setenta, de tres procesos independientes: la revolución de la tecnología de la información; la crisis económica tanto del capitalismo como del estatismo y sus reestructuraciones subsiguientes; y el florecimiento de movimientos sociales y culturales, como el antiautoritarismo, la defensa de los derechos humanos, el feminismo y el ecologismo. La interacción de estos procesos y las reacciones que desencadenaron crearon una nueva estructura social dominante, la sociedad red; una nueva economía, la economía informacional/global; y una nueva cultura, la cultura de la virtualidad real. La lógica inserta en esta economía, esta sociedad y esta cultura subyace en la acción social y las instituciones de un mundo interdependiente ${ }^{21}$.

¿Y la Educación? ¿Castells habría, por un remoto acaso, olvidado o menospreciado la educación en ese brave new world huxleyiano? Creemos que no. Simplemente porque, no obstante, los expresivos avances en las tecnologías informativa y comunicacional - que ciertamente influyeran y continúan a hacerlo cada vez más en el ámbito educativo -, las

\footnotetext{
${ }^{20}$ Apud ARAUJO, Luis. Aprendizagem organizacional no Brasil [recurso eletrônico]. Claudia Simone Antonello et. al. Porto Alegre: Bookman, 2011, [Apresentação], p. viii.

21 CASTELLS, Manuel. La Era de la Información: Economía, Sociedad y Cultura, v. III. Cambridge, Massachusetts: Blaokwell Publishers, 2001, p. 406.
} 


\section{EL MÉTODO DE ESTUDIO DE CASO O TÉCNICA CASUÍSTICA: PROPUESTA DE APLICACIÓN EN \\ UNA UNIVERSIDAD DEL VALE DO ITAJAÍ - SC - BRASIL \\ DOI: http://dx.doi.org/10.5007/1983-4535.2016v9n2p154}

metodologías didáctico-pedagógicas tradicionales parecen resistir, incólumes, a ese admirable mundo nuevo. ¿Por qué? Porque la educación, al igual que la psicología, la ingeniería, la lingüística, entre otras ciencias, dependen de la cognición (acto o proceso de conocer). Por su vez, este acto o proceso parte de un input sensorial que "es transformado, reducido, elaborado, almacenado, recobrado o utilizado. [Así, los términos] sensación, percepción, imaginación, recuerdo y solución de problemas, se refieren a etapas o aspectos hipotéticos de la cognición"22. La utilización de ese input sensorial provocará un output que será la experimentación del conocimiento, fijando en la mente el resultado alcanzado. La reexperimentación del mismo output será entonces reconocida, ya que anteriormente registrada.

La didáctica es el arte de enseñar, o como diría Titone: "la Didáctica es la teoría de la praxis docente" 23 , definiéndola como "las síntesis orgánica y funcional de una metodología de la instrucción (fin) con una tecnología de la enseñanza (medio), la cual extrae sus fundamentos de la filosofía, de la ciencia biológica, psicológica y sociológica y de la experiencia personal e histórica, ayudada por la experiencia científico-experimental [negrillas nuestras] ${ }^{, 24}$. Es decir, la didáctica necesariamente depende de la experiencia (personal, histórica y científico-experimental) para que así sea interpretada; si así no lo fuera, no sería didáctica, sino mera transmisión de conocimientos teóricos, apriorísticos. En sentido similar es el entendimiento de Vasquez: "tanto la teoría construida como las reflexiones críticas deben tener como parámetro epistemológico la relación con la práctica y ser orientadas por la Filosofía de la praxis"25.

Teoría y práctica han existido desde siempre como opuestos, antagónicos. Ambos conceptos deben ser aplicados, como preocupación central, a la formación de profesores desde "el punto de vista del papel desempeñado por teoría y práctica en ese campo" ${ }^{26}$. Esta

\footnotetext{
22 OCAÑA, Alexander Luis Ortiz. Aprendizaje y comportamiento basados en el funcionamiento del cerebro humano: emociones, procesos cognitivos, pensamiento e inteligencia. Hacia una teoría del aprendizaje neuroconfigurador [recurso electrónico]. Disponible en: $<$ https://books.google.com.br/books? id=8md4zRdV2kwC\&pg=PA3\&dq=teor $\% \mathrm{C} 3 \% \mathrm{ADa}+$ praxis + did $\% \mathrm{C} 3 \% \mathrm{~A} 1 \mathrm{c}$ tica+pedagog $\% \mathrm{C} 3 \% \mathrm{ADa}+$ universidad $\& \mathrm{hl}=$ pt-BR\&sa $=$ X\&ei=nKZQVbHIK-uIsQS -

IHgBQ\&ved=0CBwQ6AEwAA\#v=onepage \&q=teor $\% \mathrm{C3} \% \mathrm{ADa} \% 20$ praxis $\% 20 \mathrm{did} \% \mathrm{C3} \% \mathrm{~A} 1 \mathrm{ctica} \% 20$ pedagog $\% \mathrm{C} 3 \% \mathrm{ADa} \% 20$ universidad\&f=false $>$. Acceso en: Mayo.2015, pp. 11-12.

${ }^{23}$ Apud ESCRIBANO GONZÁLEZ, Alicia. Aprender a enseñar. Fundamentos de didáctica general. $2^{\mathrm{a}}$ ed. Cuenca: Ediciones de la Universidad de Castilla-La Mancha, 2004, p. 26.

${ }^{24}$ TITONE (1981) Apud ESCRIBANO GONZÁLEZ, op.cit., pp. 26-27.

25 VASQUEZ (1977) apud CHAVES, Márcia; GAMBOA, Silvio Sánchez. Prática de ensino: formação profissional e emancipação. 2a edição. Maceió: Universidade Federal de Alagoas/EDUFAL, 2000, p. 133.

${ }^{26}$ DE SOUZA, Helena Beatriz Mascarenhas. Contra o desperdicio da experiência: pelo diálogo entre teoria e prática na formação de professores, na perspectiva da profissionalidade docente. In: "Práticas inovadoras na
} 


\section{EL MÉTODO DE ESTUDIO DE CASO O TÉCNICA CASUÍSTICA: PROPUESTA DE APLICACIÓN EN \\ UNA UNIVERSIDAD DEL VALE DO ITAJAÍ - SC - BRASIL \\ DOI: http://dx.doi.org/10.5007/1983-4535.2016v9n2p154}

asertiva recibe, no raramente, un ropaje de negatividad al ser usualmente destacado que lo teórico mucho se aproxima de lo inútil. Y esto tanto es rotulado por docentes como por discentes, a través de la desgastada frase "esto es muy bonito en la teoría, pero quiero ver en la práctica! "27 ¿Cuántas veces no oímos o no dijimos esto? La verdad es que gran parte de la culpa por esa negatividad de la teoría está insertada en el propio curso de formación del docente, cuyo currículo lleva en sí un volumen considerablemente elevado de pura teoría. En este sentido, destaca De Souza: "El problema [...] no está en que los programas de formación inicial de profesores trabajen con una dosis elevada de contenidos teóricos, y sí en el hecho de que estos sean de modo general descontextualizados, desorientados, desvinculados y desarticulados de la práctica docente sobre la cual teorizan" 28 .

Supuesto esto, vale destacar en primer lugar, que dicha constatación ha dado lugar a argumentos traducidos por frases como "he aprendido más con la práctica de la docencia, que con la teoría”, lo que de modo algún autoriza a que se desprecie la teoría como inútil, o aún, a que se aumente el número de horas de clases prácticas disminuyéndose las horas destinadas a la teoría. En sentido práctico, esta comprensión nos lleva a ratificar un importante axioma: la teoría sin la práctica dificulta la asimilación y adherencia del conocimiento; la práctica sin la teoría, por otro lado, es pura verbalización inconsistente ${ }^{29}$. Con otros términos, Saviani nos expone algo similar:

En el interior de la oposición teoría-práctica se insinúa la oposición verbalismoactivismo: lo que se opone de modo excluyente a la teoría no es la práctica, sino el activismo; del mismo modo, lo que se opone de modo excluyente a la práctica es el verbalismo y no la teoría. Pues el activismo es la "práctica" sin teoría y el verbalismo es la "teoría" sin la práctica. Es decir: el verbalismo es el hablar por hablar, el blablablá, el culto de la palabra hueca; y el activismo es la acción por la acción, la práctica ciega, el actuar sin rumbo claro, la práctica sin objetivo. ${ }^{30}$

¿A fin de cuentas, la psicología de la educación es un arte o una ciencia? Ni uno ni otra, o mejor, es el resultado de ambas, arte y ciencia. Nadie nace sabiendo, aprende a partir de sus primeros pasos, guiado por sus progenitores o responsables, después por sus profesores y por el contacto directo con la acción práctica, i.e., practicando y asimilando (usando como

aula universitária. Possibilidade, desafios e perspectivas”, Beatriz Maria Boéssio Atrib Sanchet, Gomercindo Ghiggi (Org.). São Luis, MA: EDUFMA, 2009, p.48.

${ }^{27}$ Ibidem, p. 48.

${ }^{28}$ Ibidem, p. 49.

${ }^{29}$ KOFFLER, J. Y. O homem: esse projeto mal-acabado. Blumenau: FURB, jul. 1976. Palestra ministrada a alunos do $9^{\circ}$ semestre do Curso de Administração de Empresas.

30 SAVIANI, Demerval. Pedagogia: o espaço da educação na universidade. In: Cadernos de Pesquisa, jan./abr. 2007, v. 37, n.130. Campinas, SP: Autores Associados, 2007, p. 109. 


\section{EL MÉTODO DE ESTUDIO DE CASO O TÉCNICA CASUÍSTICA: PROPUESTA DE APLICACIÓN EN \\ UNA UNIVERSIDAD DEL VALE DO ITAJAÍ - SC - BRASIL \\ DOI: http://dx.doi.org/10.5007/1983-4535.2016v9n2p154}

parámetro sus propias experiencias vivenciales) lo que otros individuos a su alrededor practican. Piaget, Host, entre otros estudiosos, ya concluían en sus respectivas tesis que el acto de investigar acciona las estructuras intelectuales pari passu con las conceptualizaciones que le sirven de punto de partida, complementando que, de la conjugación de estas estructuras y conceptos con los resultados de la investigación se erigen "procesos de reestructuración y de construcción conceptual, es decir, de aprendizaje y desarrollo intelectual” ${ }^{\text {"31 }}$. Si el constructo investigación se compone de un conjunto de procesos complejos (exploración, observación, experimentación, etc.) que objetivan alcanzar como fin el conocimiento de la realidad, parécenos indispensable que tales procesos sean complementados por una actividad práctica exterior, a fin de ratificar (o rectificar) las hipótesis que los fundamentan.

Abramos un necesario paréntesis explicativo. ¿Cuál es la cuna de la educación formal (escolar), en términos modernos? En Brasil - y con bastantes similitudes en nuestro continente - es apenas en la década de 1920 que la pedagogía tradicional comienza a ceder espacio a una versión pedagógica moderna, coincidente con la creación de la Associação Brasileira de Educação (ABE). El surgimiento de la Faculdade de Filosofia, Ciências e Letras da Universidade de São Paulo (USP) se da apenas en 1934 con la formalización de la ciencia Didáctica como disciplina de formación de profesores universitarios, substituyendo el prerrequisito anterior de formación pedagógica como necesario al ejercicio del magisterio. La licenciatura en Didáctica pasa a ser un curso independiente en 1941, exigiendo la conclusión previa del Bachillerato. Un largo periodo (Estado Novo) se sigue, durante el cual la educación queda subsumida a los intereses conservadores de la sociedad, dirigidos por injerencias de rasgo político. La fase comprendida entre 1945 y 1960 es la que abrirá espacio para las nuevas ideas y la Didáctica, en harmonía con sensibles alteraciones en los modelos político (democracia liberal más o menos clásica) y económico (“aceleración y diversificación del proceso de substitución de importaciones y la penetración del capital extranjero") ${ }^{32}$.

Fácil observar que nuestra educación moderna es joven (poco más de medio siglo) y persiste en mantener un perfil excesivamente dependiente del dominio político, con las naturales consecuencias derivadas de sus constantes mudanzas de humor. Muy probablemente sea éste el principal elemento causador de los grandes y renitentes males que asolan la

${ }^{31}$ PIAGET (1969), HOST (1978) Apud SACRISTÁN, José Gimeno. Las posibilidades de la investigación educativa en el desarrollo del curriculum y de los profesores. In: Revista de Educación, n. 284, septiembrediciembre 1987. Madrid: Ministerio de Educación y Ciencia/Ciudad Universitaria, 1987, p. 274.

${ }^{32}$ VEIGA, Ilma Passos Alencastro. A prática pedagógica do professor de didática. 11 ed. Campinas, SP: Papirus, 1989, pp. 46-53. 


\section{EL MÉTODO DE ESTUDIO DE CASO O TÉCNICA CASUÍSTICA: PROPUESTA DE APLICACIÓN EN \\ UNA UNIVERSIDAD DEL VALE DO ITAJAÍ - SC - BRASIL \\ DOI: http://dx.doi.org/10.5007/1983-4535.2016v9n2p154}

educación brasileña y sus congéneres latinoamericanas. Una ponencia de Vásquez Lucero ${ }^{33}$ reproduce muy próximo de lo fiel, los principales problemas que afligen la educación en nuestro continente, como expuesto en la Ilustración 2.

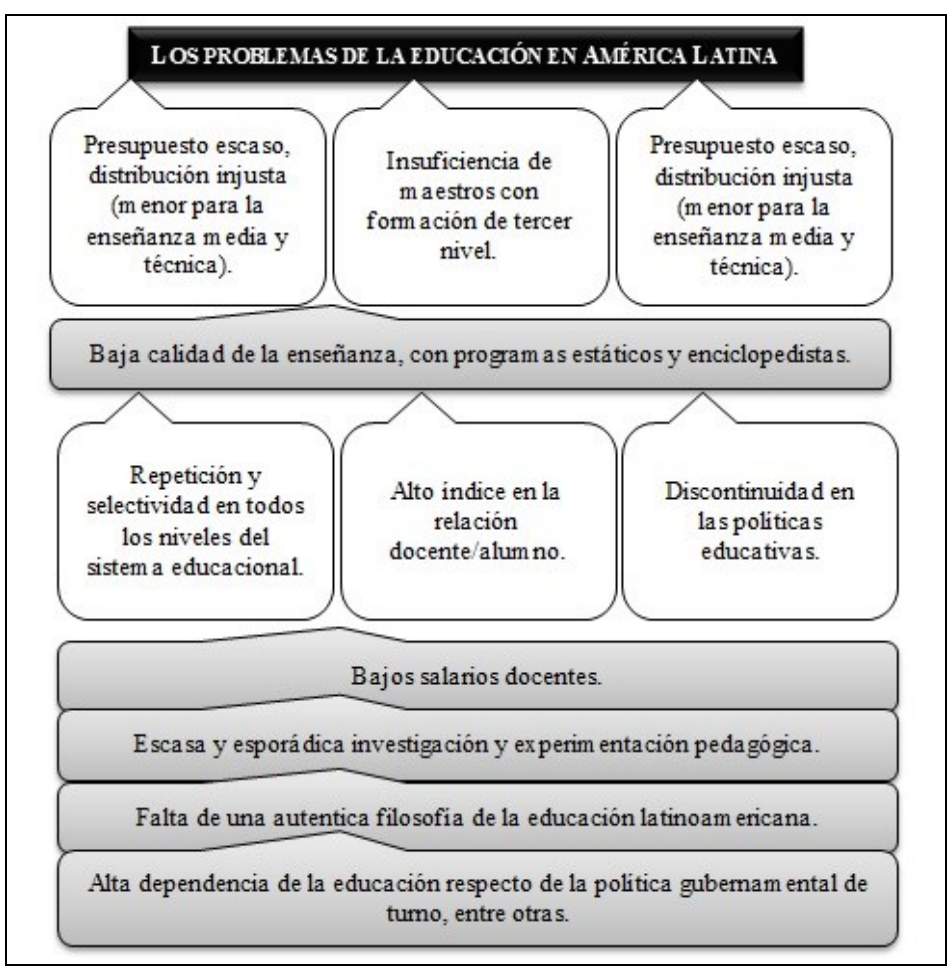

Ilustración 2 Problemas de la educación - América Latina. Fuente: Adaptado de Vásquez (2005, p. 31).

La mención, en la ilustración arriba, de la falta de una autentica filosofía de la educación latinoamericana, refiere la necesidad de ajustes de nuestras políticas educativas a la realidad del continente, aunque sin perder de vista los avances didáctico-pedagógicos que ocurren en los centros más afamados y tradicionales de la enseñanza. Son dos puntos distintos, pero que a la vez se complementan: la atención a nuestra realidad continental (geopolítica y social), en estrecho compás con la aplicación de las nuevas tecnologías y metodologías educativas que rigen en los centros más desarrollados y avanzados. Esto no significa que debamos copiar modelos prontos y terminados para otras realidades, sino que tenemos la necesidad de crear, de una vez por todas, nuestras propias metodologías que efectivamente atiendan a nuestras necesidades y demandas de crecimiento como nación, en

\footnotetext{
${ }^{33}$ VÁSQUEZ LUCERO, Elbia Myrian. Principios y Técnicas de Educación de Adultos. 4 reimp./1 ed. San José, C.R.: EUNED, 2005, p. 31.
} 


\section{EL MÉTODO DE ESTUDIO DE CASO O TÉCNICA CASUÍSTICA: PROPUESTA DE APLICACIÓN EN \\ UNA UNIVERSIDAD DEL VALE DO ITAJAÍ - SC - BRASIL \\ DOI: http://dx.doi.org/10.5007/1983-4535.2016v9n2p154}

amplio sentido y sin desconsiderar que hoy nuestras necesidades de ajustes son de índole globalizada.

\section{EL MÉTODO DE ESTUDIO DE CASO Y SUS FUNDAMENTOS}

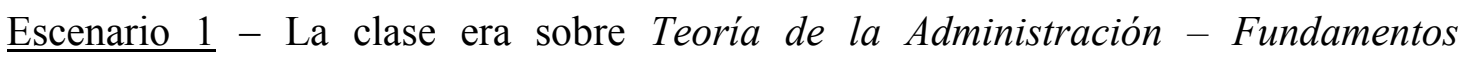
Filosóficos. El profesor entrara y observara que había doce alumnos (de un total de 21). La mayor parte estaba sentada en las proximidades de la puerta o aglutinada próxima de la pared del fondo. Pocos ocuparon las mesas frontales o intermediarias. Dos alumnos tenían puestos auriculares conectados a una computadora. El profesor inicia su clase: “Alguien sabe decirme quienes son Henri Fayol, Max Weber, Luther Gullick? Silencio absoluto. Miradas interrogativas, hasta que un alumno levanta la mano y dice: "Profesor, ¿serían por acaso administradores famosos? El profesor pensó: “FFaltan aún 40 minutos para finalizar la clase!", con cierto desaliento.

Escenario 2 - Misma situación, misma aula, mismos alumnos. El profesor entra, saluda a todos, observa por algunos segundos los alumnos que están sentados más atrás y aquellos dos con auriculares conectados a la computadora, y dice: "Perdón, ¿me engañé de clase? Los alumnos lo miran medio asustados, medio risueños. Ese hiato interruptor llama la atención de los alumnos sentados más hacia el fondo y a aquéllos que están usando auricular (que inmediatamente los retiran, para saber lo que está sucediendo). Uno de los alumnos (sentados al frente) responde: "No, profesor, ¿no se acuerda de nosotros?”, y todos ríen, incluso el profesor. Los alumnos no recolocan los auriculares, quedan atentos. El proceso en el que estaban (oír música) fuera graciosamente interrumpido. Pasado el breve momento de relajamiento (romper el hielo), el profesor retoma la palabra: "Fulano, cuando Ud. se levanta, ¿cuál es su quehacer hasta venir a la universidad? Respuesta del alumno: “Bueno, me levanto, cepillo los dientes y hago toda mi higiene personal, tomo el desayuno, arreglo mis materiales de clase y vengo para la universidad” (actividad refleja o causi refleja). El profesor: “¿Siempre es así? Alumno: “Sí, prácticamente casi siempre. Apenas cuando surge algún inconveniente, lo resuelvo y continúo con esa costumbre”. "Muy bien”, dice el profesor y prosigue: “¿Cómo lo llamaría Ud. a esto?”. "Una rutina”, responde el alumno. “iExactamente!”, ratifica el profesor. Los alumnos estaban expectantes, no sabían adónde el profesor quería llegar... La puerta de la mente se había abierto para ingresar a la explanación teórica sobre Filosofía de la Administración. 


\section{EL MÉTODO DE ESTUDIO DE CASO O TÉCNICA CASUÍSTICA: PROPUESTA DE APLICACIÓN EN \\ UNA UNIVERSIDAD DEL VALE DO ITAJAÍ - SC - BRASIL \\ DOI: http://dx.doi.org/10.5007/1983-4535.2016v9n2p154}

Esta breve escenificación adviene de un ejemplo práctico, ocurrido en clase, y como éste, existen incontables otros que se suceden en prácticamente todas las áreas del conocimiento, en todos los grados, en todas las instituciones de educación. La ilustración nada más es que la confirmación de una distorsión usual en el comportamiento del profesor ante la conducta dispersada de los alumnos. En otras palabras, el primer acto al ingresar a una clase debe ser conquistar la atención de los alumnos y, así, entablar sin tardanza un diálogo constructivo. "Los buenos profesores, por lo general, no nacen, se hacen; y se hacen poniendo en práctica los conocimientos psicológicos necesarios para asegurar el mejor aprendizaje del estudiante" 34 . Y hablar en aprendizaje redunda recordar que existen varios modelos que fundamentan teorías científicas al respecto. Modelos, por su vez, son representaciones mentales de sistemas reales con sus respectivas estructuras y funcionamientos. Pueden ser traducidos como "una estructura conceptual que se encuentra entre la explicación teórica y la descripción que nos ofrecen los datos empíricos”35. En Psicología Educacional existen varias clasificaciones de los modelos existentes, aunque dos sean los más nombrados por una mirada muy genérica: los modelos no cognitivos y los modelos cognitivos ${ }^{36}$.

En lo que concierne a la educación, la ciencia cognitiva lleva ventaja sobre los modelos no cognitivos. En el corriente siglo (XXI), la cognición humana atrae la atención de estudiosos de todos los portes y ciencias, y entre estas, la educación (el proceso científico educativo) aparece con destaque diferenciado. El desafío es formar seres humanos más capacitados y con visión inclinada hacia el futuro de la humanidad. Las preocupaciones pasan a ser constantes y crecientes en Ciencia y Tecnología bajo la perspectiva de un análisis más depurado y profundizado, tendiente a sobrevalorar comportamientos más inteligentes en sentido amplio (humanos, animales, máquinas). Todo esto en razón de una incesante demanda por mayor valoración del mundo del conocimiento, como fundamental para el futuro humano, para "las transformaciones de las necesidades humanas y para los nuevos modos de ver el universo y de discutir el desarrollo del potencial humano en niveles más avanzados y creativos" 37 . En la esfera educacional - lato sensu - tres conceptos asociados a lo expuesto

\footnotetext{
${ }^{34}$ LLERA, Jesús Beltrán. Naturaleza, desarrollo y contenido de la psicología de la educación. In: "Psicología de la Educación", J. Beltrán Llera, J. A. Bueno Álvarez (Eds.). Barcelona: MARCOMBO, 1995, p. 19.

35 ARNAL et al. (1992) Apud CABANACH, Ramón González. Modelos de aprendizaje. In: "Psicología de la Educación”, J. Beltrán Llera, J. A. Bueno Álvarez (Eds.). Barcelona: MARCOMBO, 1995, p. 288.

${ }^{36}$ Este tema merece un estudio mucho más avanzado y que, en razón de ello, exige un espacio substancialmente mayor, por lo que apenas lo mencionaremos en passant y como fuente de investigación a los interesados (N.A.).

${ }^{37}$ MOSQUERA, Juan José Mouriño. Ciência cognitiva e educação. In: "Educação superior: vivências e visão de futuro”, Délcia Enricone, Marlene Grillo (Orgs.). Porto Alegre: EDIPUCRS, 2005, p. 48.
} 


\section{EL MÉTODO DE ESTUDIO DE CASO O TÉCNICA CASUÍSTICA: PROPUESTA DE APLICACIÓN EN \\ UNA UNIVERSIDAD DEL VALE DO ITAJAÍ - SC - BRASIL \\ DOI: http://dx.doi.org/10.5007/1983-4535.2016v9n2p154}

surgen con valoración destacada: autoconcepto, rendimiento y motivación académica. Revisémoslos resumidamente.

En el terreno crítico de la Psicología y, con mayor especificidad, en relación a la cognición humana, ciertos aspectos o capacidades denotan significativa importancia. Son ellas: autoconciencia, desarrollo de teorías sobre la propia identidad (¿Qué soy? ¿Quién soy? ¿Cómo soy?, etc.), y autoevaluación con cierta dosis de criticismo ${ }^{38}$. Son cuestiones básicamente comportamentales del individuo que inducen a la necesidad de una tripartición del yo (material, espiritual y social) para que se pueda analizar en profundidad su desempeño como individuo completo. El rendimiento escolar está insertado en ese universo y mantiene fuerte conexión con el autoconcepto del individuo, en el cual, por su vez, está subsumida la autoestima. Estos dos factores comportamentales son primordiales para la educación humana, pues de ellos depende su actuación en los ámbitos social, profesional, familiar y ético-moral ${ }^{39}$. Así, alumnos constituidos de autoestima, motivación y confianza producirán un trabajo más organizado, al paso en que también presentarán mayor rentabilidad del esfuerzo ${ }^{40}$.

De esta premisa se infiere que las tareas asignadas a un determinado tipo de trabajo (labor) solo podrán ser desempeñadas de manera eficaz y productiva si las cualificaciones proporcionadas por el sistema educativo fueren conducentes y apropiadas a la formación del trabajador, independientemente de cuál sea su área de actuación. Todos los factores anteriormente destacados en nuestra exposición corriente - autoestima, motivación, confianza, rendimiento, comprometimiento, etc. - interceden, positiva o negativamente, para que la práctica laboral atienda a las expectativas alimentadas por el mercado (multifacético, altamente mutante en el sentido de su dinámica conceptual-operacional) que, al final, son reflejo fiel de los deseos, necesidades y expectativas de la sociedad en la cual está insertada la universidad y la empresa.

Sigamos ahora en dirección a nuestro objetivo central: la relación entre lo aprendido y la realidad profesional, entre la teoría y la práctica, mirando objetivamente cómo se podría garantizar al alumno una adecuada formación y capacitación para el desempeño de la profesión. Resaltemos, todavía, que nuestra intención no es recriar la rueda, sino más bien

\footnotetext{
${ }^{38}$ BALDWIN \& HOLMES (1987) Apud NUÑEZ PÉREZ, José Carlos; GONZÁLEZ-PIENDA, Julio Antonio. Determinantes del rendimiento académico. Oviedo, Asturias: Universidad de Oviedo - Servicio de Publicaciones, 1994.

${ }^{39}$ QUESADA, Rogelia Perea. Educación para la salud: reto de nuestro tiempo. Madrid: Ediciones Díaz de Santos, 2004.

${ }^{40}$ MUÑOZ-REPISO, Ana García-Varcárcel. Integración de las TIC en la docencia universitaria. Oleiros, La Coruña: NETBIBLO, 2011.
} 


\title{
EL MÉTODO DE ESTUDIO DE CASO O TÉCNICA CASUÍSTICA: PROPUESTA DE APLICACIÓN EN \\ UNA UNIVERSIDAD DEL VALE DO ITAJAÍ - SC - BRASIL \\ DOI: http://dx.doi.org/10.5007/1983-4535.2016v9n2p154
}

adecuarla al obrar educativo posmoderno, según el cual la teoría es coadyuvante de la praxis y no lo contrario. O mejor, una no dispensa la otra y viceversa; ellas se complementan cumpliendo, cada una, su función en la ecuación educativo-pedagógica.

El uso de estudios de caso como método de enseñanza "ha formado parte consustancial de la actividad docente desde, prácticamente, sus inicios. La estrategia de casos en la formación de profesionales de la abogacía, medicina o empresa ha sido una práctica común desarrollada en estos ámbitos profesionales" ${ }^{\text {, }}$, siéndole reconocida su tradición como método dinámico y aglutinador de la teoría con el empirismo. En este especial sentido, Mora \& Gómez complementan con clareza didáctica:

\begin{abstract}
La influencia de modelos clínicos de intervención educativa centrada en el individuo ha favorecido su uso como elemento diagnóstico. El caso de la intervención psicopedagógica sigue estando presidido a pesar de las valiosas y esforzadas iniciativas por ofrecer alternativas a esta situación, por un tipo de intervención centrada en casos individuales, en la que el psicopedagogo actúa como experto que, una vez realizado el diagnóstico, prescribe los tratamientos más adecuados a los sujetos (alumnos) individualmente considerados ${ }^{42}$.
\end{abstract}

En suma, el método de casos atiende a cinco presupuestos determinantes que lo tornan provechoso como aplicación psicopedagógica que facilita el aprendizaje en amplio sentido. Los cinco determinantes o ventajas pueden ser resumidos así ${ }^{43}$ :

I. Análisis críticos y resolución de problemas - Los estudios de casos permiten el desarrollo de estas capacidades (análisis crítico y resolución de problemas), desarrollando en el alumno el pensamiento estratégico.

II. Práctica reflexiva y acción deliberativa - La didáctica a través de este método facilita el análisis de situaciones mediante la diversidad de alternativas y sus planes de acción, motivando la reflexión del alumno.

III. Análisis y acción en situaciones complejas - A través del análisis de casos, el alumno pasa a familiarizarse con el método superando la rutina tradicional de la actividad docente en sus clases puramente teóricas, aguzando el desenvolvimiento de conciencias más sensibles a un contexto, minorando las diferencias individuales.

\footnotetext{
${ }^{41}$ MORA, Maria Carmen Fonseca; GÓMEZ, J. Ignacio Aguaded. Enseñar en la universidad. Experiencias y propuestas para la docencia universitaria. Oleiros, La Coruña: NETBIBLO, 2007, p. 73.

42 Ibidem, p. 74.

${ }^{43}$ Con base em Mora \& Gomes (2007), op.cit., pp. 74-75.
} 


\section{EL MÉTODO DE ESTUDIO DE CASO O TÉCNICA CASUÍSTICA: PROPUESTA DE APLICACIÓN EN \\ UNA UNIVERSIDAD DEL VALE DO ITAJAÍ - SC - BRASIL \\ DOI: http://dx.doi.org/10.5007/1983-4535.2016v9n2p154}

IV. Responsabilidad individual en el aprendizaje - El método de casos refuerza el comprometimiento del estudiante en su propio aprendizaje, pasando de mero espectador pasivo y receptor de informaciones, para activo y responsable directo por la asimilación de los enseñamientos que le son impartidos. Deja de ser un simple receptor de verdades absolutas e impuestas y asume el debate de los casos propuestos, discutiéndolos, aportando sus experiencias, sentimientos y valores personales. Es decir, pasa a ser actor de su propio aprendizaje, contribuyendo con sus juicios valorativos, experimentales y epistemológicos.

V. Aprendizaje compartido - Mediante la práctica de un estudio compartido en grupo, se impulsa la inter-colaboración entre alumnos, facilitando la resolución de problemas en régimen participativo, además de ampliar el diálogo colaborativo.

El origen del estudio de caso se sitúa en los años 30 del siglo XVIII y es acreditado a Frédéric Le Play y su experiencia en reforzar sus estudios sobre presupuestos familiares, en el ámbito de las ciencias sociales. En la alborada del siglo XX, otro estudioso - Edwin Gay - de la Escuela de Negocios de Harvard, introduce el método del caso como procedimiento adecuado a la enseñanza. La opción por esta modalidad didáctica no fue estrictamente científica, sino que advino de una necesidad: la inexistencia de libros de texto propios para un programa de posgrado en negocios. Así, la solución más racional (y al alcance de la mano) surgió de la idea de entrevistar líderes profesionales de esa área junto a los cuales, mediante entrevistas, se cogieron relatos pormenorizados de sus experiencias. De este ejercicio nació el método de estudio de caso, transformado en "enseñanza de las leyes en el área de negocios"44.

Explícanos Zebala \& Arnau, que el método de caso es razonablemente simple, aunque inteligente y efectivo. Puede ser sintetizado como siendo el análisis de cierta situación real sometida a los alumnos de una clase para que, mediante su debate crítico, lléguese a soluciones plausibles y defendibles. Cuando la Universidad de Harvard, comprobada la eficacia del método - tanto en su aspecto teórico como empírico -, ratificó su validad y viabilidad práctica como método de enseñanza, optó por condensar casos prácticos en ediciones didácticas, las cuales en poco tiempo ultrapasaron las fronteras del país, pasando a ser utilizadas en todo el mundo. "A partir de ese momento, el método fue ampliamente

\footnotetext{
${ }^{44}$ ZABALA, Antonio; ARNAU, Laia. Métodos para la enseñanza de las competencias. Barcelona: Editorial GRAÓ, de IRIF, 2014, p. 132.
} 


\section{EL MÉTODO DE ESTUDIO DE CASO O TÉCNICA CASUÍSTICA: PROPUESTA DE APLICACIÓN EN \\ UNA UNIVERSIDAD DEL VALE DO ITAJAÍ - SC - BRASIL \\ DOI: http://dx.doi.org/10.5007/1983-4535.2016v9n2p154}

utilizado en múltiples especialidades formativas, entre las que se destacan el derecho, la administración de empresas, la medicina y las ciencias políticas"45.

En suma, el método de estudio de caso parte, generalmente, del análisis de un problema real (o elaborado), propuesto a los estudiantes para su análisis, discusión y proposición de soluciones. Como método de enseñanza, es innegable su validez desde que se tome el cuidado de comparar resultados entre diversas fuentes de evidencias del fenómeno estudiado a fin de poner a prueba la calidad de los datos empíricos durante la colecta de datos $^{46}$. Lo que nos interesa saber ahora, es dónde se inserta nuestro objetivo de análisis en la práctica del método de estudio de casos, como tesis defendida en formato de propuesta, en este artículo.

\subsection{LA APLICABILIDAD PRÁCTICA DEL MÉTODO DE ESTUDIO DE CASO: NUESTRA PROPUESTA}

¿Cuál sería hoy, bajo la óptica de la educación posmoderna y de las nuevas demandas de un mercado globalizado, el(los) gran(des) problema(s) o impase(s) para el binomio enseñanza $x$ aprendizaje en la Universidad? El espacio físico (de páginas) disponible no nos permite que profundicemos nuestro análisis, pero, por absoluta necesidad, debemos contextualizar el tema dentro de un escenario más amplio que permita al lector comprender los desafíos de una nueva propuesta didáctico-pedagógica.

Como preámbulo sumario, es menester citar las doce necesidades psicopedagógicas que identifican las referencias del niño (en base al estudio del Centre de Recherche $e$ d'Innovation en Sociopédagogie familiale et scolaire [Ceris], de Mons) y que componen un paradigma compuesto por cuatro dimensiones: afectiva, cognitiva, social y de valores. Cada una de esas dimensiones, por su vez, congrega tres necesidades específicas del niño, en estrecha relación con categorías de actitudes en los padres, conformando un conjunto de probables interacciones ${ }^{47}$.

En cuanto las necesidades afectivas se relacionan con las necesidades de filiación (historia familiar y social), las necesidades de realización reflejan el campo cognitivo que acompaña el individuo en su desarrollo, complementada por la necesidad de autonomía social

\footnotetext{
${ }^{45}$ ZABALA; ARNAU (2014), op.cit., p. 132.

${ }^{46}$ GUEDES, Ana Lúcia. Pesquisa internacional em gestão: abordagem interdisciplinar com múltiplos níveis de análises. In: "Pesquisa qualitativa em administração: teoria e prática", Marcelo Milano Falcão Vieira, Deborah Moraes Zouain (Orgs.). Rio de Janeiro: Editora FGV, 2005.

${ }^{47}$ POURTOIS, Jean-Pierre; DESMET, Huguette. A educação pós-moderna. São Paulo: Edições Loyola, 1999.
} 


\section{EL MÉTODO DE ESTUDIO DE CASO O TÉCNICA CASUÍSTICA: PROPUESTA DE APLICACIÓN EN \\ UNA UNIVERSIDAD DEL VALE DO ITAJAÍ - SC - BRASIL \\ DOI: http://dx.doi.org/10.5007/1983-4535.2016v9n2p154}

(individualización) y la necesidad de valores (ideología). En estos valores, que fundamentan su felicidad, se destacan: lo bueno/el bien (moral y ética), lo verdadero (verdad) y lo bello

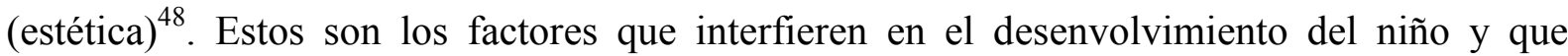
colaboran para la construcción "de su persona en el contexto del micro-medio educativo familiar" ${ }^{\prime 9}$, aunque también en otros medios, como el de su educación a lo largo de su vida como estudiante. La infancia, digamos, es la base estructural experimental, visto que todo su aprendizaje adviene de su práctica (en su medio) que, por su vez, es el espejo de las acciones acaecidas en el ámbito familiar, cuyo origen se confunde con el entorno social. Esta será su herencia cognitiva a lo largo de su vida e interferirá, directa o indirectamente, en su formación, en sus acciones y en sus tendencias comportamentales. Así, cuando nos deparamos con nuestros alumnos en clase, en la universidad, debemos mantener siempre presente en nuestra mente que estamos ante un conjunto polifacético de individuos cuyas experiencias vivenciales reflejan todo un histórico de vida desde la infancia. Sin duda, una tarea que pocos docentes suelen practicar.

Es en base a esta pluralidad intelectual-vivencial que, en lo concerniente a las metodologías pedagógicas, pensamos en abrir espacio exploratorio a nuevas técnicas híbridas, a partir de la experiencia de inserción del método de estudio de caso como didáctica asociada a las técnicas tradicionales en práctica masificada. Vale recordar que, en el sistema tradicional de enseñanza (sentido lato), se exige del alumno un mayor volumen de memorización, mientras se descuida del raciocinio lógico, usualmente exigido en la técnica del método de caso. Vale recordar que las TICs, en muchos casos, inhiben el raciocinio lógico (capacidad de pensar, de resolver problemas, de crear), imponiendo que se privilegie una pedagogía que promueva la autoría, reconociendo al alumno como protagonista del acto educativo.

Nuestro desafío experimental a ser aplicado en una de las universidades del Vale do Itajaí (SC - Brasil) - en la cual desempeñamos las funciones acumuladas de docencia y coordinación de área - se compone de las siguientes acciones-etapas:

I. Definir dos áreas del conocimiento en las cuales se aplicará la experiencia: Ya están definidas las áreas de Administración de Empresas y Derecho.

\footnotetext{
${ }^{48}$ Ibidem.

${ }^{49}$ POURTOIS; DESMET (1999), op.cit., p. 65.
} 


\section{EL MÉTODO DE ESTUDIO DE CASO O TÉCNICA CASUÍSTICA: PROPUESTA DE APLICACIÓN EN \\ UNA UNIVERSIDAD DEL VALE DO ITAJAÍ - SC - BRASIL \\ DOI: http://dx.doi.org/10.5007/1983-4535.2016v9n2p154}

II. Escoger, en cada una de ellas, dos clases específicas: una denominada grupo experimental, cuyo objetivo es la validación del método de estudio de caso, y la otra denominada grupo de control, regida por el método tradicional.

III. Las materias que se impartirán en las clases, en cada uno de los dos grupos, serán exactamente las mismas.

IV. El periodo de aplicación de la investigación está determinado para ocurrir en el primer semestre de 2016. Subráyese que, aunque parezca corto, tal periodo es considerado suficiente para fundamentar una eventual replicación en periodo más largo, caso los resultados de la experiencia demuestren esa necesidad.

V. Al término de ese periodo, se tabularán los datos recogidos en la experiencia, analizándolos y emitiendo el Informe Final de Evaluación, con base en el cual se pretende desenvolver una obra didáctica al respecto

VI. La metodología de aplicación seguirá los siguientes parámetros:

a. Preparación de clases sobre determinados temas, asociándolos a casos prácticos previamente compilados para el experimento. En esta etapa, los conceptos básicos que componen el tema serán separados y servirán para utilización como directrices semánticas. Ejemplo: (a) Tema: Entrepreneurship (quehacer empresarial); (b) Conceptos básicos: empresario, emprender, estrategia, investigación de mercado, etc. (c) Dichas directrices semánticas deberán ser conceptuadas por los alumnos y comparadas con sus conceptos académicos; etc.

b. El caso práctico será sintetizado y distribuido a los alumnos para su análisis, consideraciones prácticas y decisiones. Esta etapa será analizada y discutida en clase, utilizando el ejemplo del caso práctico. De ella advendrán: (I) la presentación/discusión de las directrices semánticas; (II) la discusión comparativa de las soluciones propuestas; (III) la discusión de los eventuales desvíos analíticos y su corrección.

c. La aplicabilidad práctica de las soluciones propuestas será replicada en casos de coyuntura similar a fin de trazar inferencias comparativas.

Resumidamente, esta es nuestra propuesta metodológica a ser experimentada en la práctica, buscando el principal objetivo de tornar las clases más dinámicas y participativas, y con mayor protagonismo del alumno en su proceso de instrucción. 


\section{EL MÉTODO DE ESTUDIO DE CASO O TÉCNICA CASUÍSTICA: PROPUESTA DE APLICACIÓN EN \\ UNA UNIVERSIDAD DEL VALE DO ITAJAÍ - SC - BRASIL \\ DOI: http://dx.doi.org/10.5007/1983-4535.2016v9n2p154}

\section{REFERENCIAS BIBLIOGRÁFICAS}

ABRES - Associação Brasileira de Estágios. Matrículas na Educação. Disponível em: $<$ http://www.abres.org.br/v01/stats/>. Acesso em: Maio.2015.

AMARAL, Nelson Cardoso. A educação superior brasileira: dilemas, desafios e comparações com os países da OCDE e do BRICS. In: $36^{\text {a }}$ Reunião Nacional da ANPEd - 29 de setembro a 2 de outubro. Goiânia: ANPEd, 2013.

ANUIES - Asociación Nacional de Universidades e Instituciones de Educación Superior - La educación superior en el siglo XXI. Líneas estratégicas de desarrollo. México, DF: ANUIES, 2000.

ARAUJO, Luis. Aprendizagem organizacional no Brasil [recurso eletrônico]. Claudia Simone Antonello et. al. Porto Alegre: Bookman, 2011, [Apresentação].

BENITO, Agueda; CRUZ, Ana. Nuevas claves para la Docencia Universitaria en el espacio europeo de Educación Superior. Madrid: NARCEA Ediciones; Universidad Europea de Madrid, 2005.

BRASIL - MINISTÉRIO DA EDUCAÇÃO. Plano Nacional de Educação - PNE.

Disponível em:

$<$ http://portal.mec.gov.br/index.php?option $=$ com_content\&id=16478\&Itemid=1107>. Acesso em: Abril.2015.

CABANACH, Ramón González. Modelos de aprendizaje. In: "Psicología de la Educación", J. Beltrán Llera, J. A. Bueno Álvarez (Eds.). Barcelona: MARCOMBO, 1995.

CASTELLS, Manuel. La Era de la Información: Economía, Sociedad y Cultura, v. III. Cambridge, Massachusetts: Blaokwell Publishers, 2001.

CHAVES, Márcia; GAMBOA, Silvio Sánchez. Prática de ensino: formação profissional e emancipação. $2^{a}$ edição. Maceió: Universidade Federal de Alagoas/EDUFAL, 2000.

DE SOUZA, Helena Beatriz Mascarenhas. Contra o desperdício da experiência: pelo diálogo entre teoria e prática na formação de professores, na perspectiva da profissionalidade docente. In: "Práticas inovadoras na aula universitária. Possibilidade, desafios e perspectivas", Beatriz Maria Boéssio Atrib Sanchet, Gomercindo Ghiggi (Org.). São Luis, MA: EDUFMA, 2009.

ENGELS \& MOROSINI (2007) Apud VITÓRIA, M. I. C.; CHRISTOFOLI, M. C. P. Estratégias didáticas com grandes grupos. In: "Capacitação docente: um movimento que se faz compromisso", Ana Lúcia Souza de Freitas [et al] (Orgs.). Porto Alegre: EDIPUCRS, 2010 .

ESCRIBANO GONZÁLEZ, Alicia. Aprender a enseñar. Fundamentos de didáctica general. $2^{\mathrm{a}}$ ed. Cuenca: Ediciones de la Universidad de Castilla-La Mancha, 2004. 


\section{EL MÉTODO DE ESTUDIO DE CASO O TÉCNICA CASUÍSTICA: PROPUESTA DE APLICACIÓN EN \\ UNA UNIVERSIDAD DEL VALE DO ITAJAÍ - SC - BRASIL \\ DOI: http://dx.doi.org/10.5007/1983-4535.2016v9n2p154}

GANDINI, Verónica. Una mirada a la situación actual de la Educación Superior Mundial y su tendencia. In: Academia.edu. 2013. Disponible en: <

http://www.academia.edu/5147698/Una_mirada_a_la_situaci\%C3\%B3n_actual_de_la_Educa ci\%C3\%B3n_Superior_Mundial_y_su_tendencia>. Acceso en: Abril.2015.

GUEDES, Ana Lúcia. Pesquisa internacional em gestão: abordagem interdisciplinar com múltiplos níveis de análises. In: "Pesquisa qualitativa em administração: teoria e prática", Marcelo Milano Falcão Vieira, Deborah Moraes Zouain (Orgs.). Rio de Janeiro: Editora FGV, 2005.

KOFFLER, J. Y. O homem: esse projeto mal-acabado. Blumenau: FURB, jul. 1976. Palestra ministrada a alunos do $9^{\circ}$ semestre do Curso de Administração de Empresas.

LUCARELLI, Elisa. Las prácticas innovadoras en el aula universitaria: Una mirada desde la investigación. In: "Práticas inovadores na aula universitária. Possibilidades, desafíos e perspectivas". Beatriz Maria Boéssio Atrib Sanchet; Gomercindo Ghiggi (Orgs.). São Luis, MA: EDUFMA, 2009.

LLERA, Jesús Beltrán. Naturaleza, desarrollo y contenido de la psicología de la educación. In: "Psicología de la Educación", J. Beltrán Llera, J. A. Bueno Álvarez (Eds.). Barcelona: MARCOMBO, 1995.

MELO, Márcia Maria de Oliveira. Repercussões do conhecimento didático sobre a formação de professores universitários em curso de atualização docente. In: "Reflexões e práticas em pedagogia universitária", Maria Isabel da Cunha (Org.). Campinas, SP: Papirus, 2007.

MORA, Maria Carmen Fonseca; GÓMEZ, J. Ignacio Aguaded. Enseñar en la universidad. Experiencias y propuestas para la docencia universitaria. Oleiros, La Coruña: NETBIBLO, 2007.

MOSQUERA, Juan José Mouriño. Ciência cognitiva e educação. In: "Educação superior: vivências e visão de futuro", Délcia Enricone, Marlene Grillo (Orgs.). Porto Alegre: EDIPUCRS, 2005.

MUÑOZ-REPISO, Ana García-Varcárcel. Integración de las TIC en la docencia universitaria. Oleiros, La Coruña: NETBIBLO, 2011.

NUÑEZ PÉREZ, José Carlos; GONZÁLEZ-PIENDA, Julio Antonio. Determinantes del rendimiento académico. Oviedo, Asturias: Universidad de Oviedo - Servicio de Publicaciones, 1994.

OCAÑA, Alexander Luis Ortiz. Aprendizaje y comportamiento basados en el funcionamiento del cerebro humano: emociones, procesos cognitivos, pensamiento e inteligencia. Hacia una teoría del aprendizaje neuroconfigurador [recurso electrónico]. Disponible en:

$<$ https://books.google.com.br/books?id=8md4zRdV2kwC\&pg=PA3\&dq=teor\%C3\%ADa+pra $\mathrm{xis}+\mathrm{did} \% \mathrm{C} 3 \% \mathrm{~A} 1 \mathrm{ctica}+$ pedagog\%C3\%ADa+universidad\&hl=pt-

BR\&sa $=$ X\&ei=nKZQVbHIK-uIsQS_- 


\section{EL MÉTODO DE ESTUDIO DE CASO O TÉCNICA CASUÍSTICA: PROPUESTA DE APLICACIÓN EN \\ UNA UNIVERSIDAD DEL VALE DO ITAJAÍ - SC - BRASIL \\ DOI: http://dx.doi.org/10.5007/1983-4535.2016v9n2p154}

IHgBQ\&ved=0CBwQ6AEwAA\# $\mathrm{v}=$ onepage $\& \mathrm{q}=$ teor $\% \mathrm{C} 3 \% \mathrm{ADa} \% 20 \mathrm{praxis} \% 20 \mathrm{did} \% \mathrm{C} 3 \% \mathrm{~A} 1$ ctica\%20pedagog\%C3\%ADa\%20universidad\&f=false>. Acceso en: Mayo.2015.

PIAGET (1969), HOST (1978) Apud SACRISTÁN, José Gimeno. Las posibilidades de la investigación educativa en el desarrollo del curriculum y de los profesores. In: Revista de Educación, n. 284, septiembre-diciembre 1987. Madrid: Ministerio de Educación y Ciencia/Ciudad Universitaria, 1987.

POURTOIS, Jean-Pierre; DESMET, Huguette. A educação pós-moderna. São Paulo: Edições Loyola, 1999.

QUESADA, Rogelia Perea. Educación para la salud: reto de nuestro tiempo. Madrid: Ediciones Díaz de Santos, 2004.

SAVIANI, Demerval. Pedagogia: o espaço da educação na universidade. In: Cadernos de Pesquisa, jan./abr. 2007, v. 37, n.130. Campinas, SP: Autores Associados, 2007.

SCHEIBEL, Maria Fani. Didática, identidade profissional e contextualização da prática docente. In: "Didática: Organização do trabalho pedagógico", Ana Claudia Urban, Christiane M. Maia, Maria Fami Scheibel. Curitiba: IESDE Brasil, 2009.

SILVA, Vanius Paiva Zaiden. Formação didático-pedagógica do professor universitário: uma necessidade? Consuelo Campos Monteiro (Orientadora). In: Fundação Aprender. Varginha: APRENDER, 2006 [documento eletrônico].

TOBÓN, S.; RIAL, A.; CARRETERO, M. A..; GARCÍA, J. A. Diseño y gestión de módulos por competencias en educación superior. In: "Competencias, calidad y educación superior", José Vicente Joven Núñez (Dir.Ed.). Bogotá: Cooperativa Editorial Magisterio, 2006.

UNESCO-PARIS. La educación superior en el siglo XXI. Visión y acción. Paris: UNESCO, 1998. Disponible en: < http://unesdoc.unesco.org/images/0011/001163/116345s.pdf>. Acceso en: Abril.2015.

VÁSQUEZ LUCERO, Elbia Myrian. Principios y Técnicas de Educación de Adultos. 4 reimp./1 ed. San José, C.R.: EUNED, 2005.

VEIGA, Ilma Passos Alencastro. A prática pedagógica do professor de didática. 11 ed. Campinas, SP: Papirus, 1989.

ZABALA, Antonio; ARNAU, Laia. Métodos para la enseñanza de las competencias. Barcelona: Editorial GRAÓ, de IRIF, 2014. 